\title{
The businesscase for ergonomic changes in health care: calculating and predicting financial outcome for ergonomic changes and innovations in health care: interactive businesscase modelling
}

\author{
Knibbe, J.J., ${ }^{*}$ N.E.Knibbe, ${ }^{1}$ \\ LOCOmotion, Research in Health Care, Brinkerpad 29, 6721 WJ Bennekom, The Netherlands.
}

\begin{abstract}
Research can point to new opportunities and assist in the development of valid business cases to help nurse managers plan change and allocate their budgets to the most promising interventions. These business cases and their results will, in turn, pave the way for more in depth and more fundamental research into implementation processes. It will add to the body of knowledge of intervention research and ultimately hopefully also add to our understanding of why ergonomic interventions in the workplace will or will not be effective and what the impact of financial constraints is. It is difficult to develop and design a valid businesscase. This poster will present one of the possible strategies to develop one.
\end{abstract}

Keywords: innovation; implementation; back pain; patient handling; ergonomic approach; nursing

\section{Introduction}

Business cases can help to convince nurse managers to undertake a prevention program in occupational health care. This is still necessary as the prevalence of occupational back pain is still high in the nursing profession.

Occupational back pain among nurses still leads to high costs for health care facilities and personal suffering for nurses. In order to reduce this problem a national approach was undertaken in the Netherlands by means of so-called convenants. In each health care sector agreements supported by signed commitment by all relevant parties led to the development of guidelines for practice and considerable support for the implementation process. It was obvious that data collection on such a large scale has problems of its own, but is also tempting and unique given the scale.

The results from four different and partly independent sources demonstrate improvement and therefore converge in their conclusions $[1,2]$. They also indicate that full compliance is not met, not even after four years.

\section{Method}

The results of these studies have also paved the way for more in depth research and contribute to our knowledge of complex implementation processes and our understanding of the effect of ergonomic interventions. As one of the results interactive business cases were developed and validated and 17 ergo-

${ }^{*}$ Corresponding author. E-mail: j.j.knibbe@planet.nl

${ }^{11}$ LOCOmotion, www.locomotion.nu 
nomic innovations reducing the exposure level are now being implemented in order to further reduce the exposure level for nurses $[2,3]$.

With the aggregated data from the large scale national monitoring and with the analysis of data on facility level it was possible to develop business cases and interactive calculating models to enable nurse managers to test, simulate and monitor their own progress and investments in equipment and training. This helps them to plan the most effective and efficient intervention policy and ensure long term changes in policy.

\section{Results}

These data also pinpointed to areas in which further reduction of exposure level could be obtained. As a direct results several innovations have been tested and also integrated into the business case and subbusiness cases with separate interactive calculating models based on Microsoft Exel. They are available for free on the internet. They demonstrated considerable reduction in exposure of nurses to manual handling, static load and pushing and pulling without compromising the quality of care for our patients. Examples of this are 'washing-without-water', ergonomic design of incontinence pads, shower- and bathing equipment and special bed- and mattress designs.

The results and the evaluation of this series of business cases was assessed by means of an online survey among a random group of 147 nurse managers. These results will be presented on the poster $[2,3]$.

\section{Conclusions}

Research and monitoring on a national scale can, in spite of its obvious flaws, point to new opportunities and assist in the development of valid business cases to help nurse managers plan change and allocate their budgets to the most promising interventions. These business cases and their results will, in turn, pave the way for more in depth and more fundamental research into implementation processes. It will add to the body of knowledge of intervention research and ultimately hopefully also add to our understanding of why ergonomic interventions in the workplace will or will not be effective and what the impact of financial constraints is.

\section{References}

[1] Knibbe et al., 2008, Fourth national monitoring, social parties in health care, the Hague, Bennekom, CAOP/ LOCOmotion.

[2] Knibbe, JJ, NE Knibbe. F. Van Vught, 2008, Markante Marges, the financial impact of innovations in health care, Stichting RegioPlus, Innovatieplatform Zorg, Zoetermeer.

[3] Knibbe et al., 2009, InnovationMirror, the impact of ergonomic innovations in a series of business case models, the Hague, Bennekom, CAOP/ LOCOmotion (www.innovatiespiegel.nl) 